\title{
Study on Lignin Isolation from Oil Palm Empty Fruit Bunches
}

\author{
Nurcahyo Iman Prakoso a , Suryo Purwono ${ }^{b}$, Rocmadi $^{\text {b }}$ \\ ${ }^{a}$ Progran Studi Kimia, Universitas Islam Indonesia \\ b Jurusan Teknik Kimia, Universitas Gadjah Mada \\ Email: nurcahyo.ip@uii.ac.id
}

\begin{abstract}
ABSTRAK
Telah dilakukan studi tentang isolasi lignin dari tandan kosong kelapa sawit dengan metode batch. Diharapkan melalui studi ini dapat memperoleh metode isolasi lignin yang optimal. Studi yang dilakukan meliputi optimasi suhu reaksi, rasio massa $\mathrm{NaOH}$ terhadap pelarut, rasio serabut terhadap pelarut, dan waktu reaksi. Dari semua perlakuan, didapatkan bahwa suhu reaksi, tekanan, konsentrasi $\mathrm{NaOH}$, rasio serabut terhadap pelarut dan waktu reaksi optimum berturut-turut yaitu, $170{ }^{\circ} \mathrm{C}, 15 \mathrm{~atm}$, $1 \%(\mathrm{~b} / \mathrm{v}), 9 \%(\mathrm{~b} / \mathrm{v})$, dan reaksi dilakukan selama $5 \mathrm{jam}$.
\end{abstract}

Kata Kunci : lignin, isolasi, tandan kosong kelapa sawit.

\begin{abstract}
Study on lignin isolation from oil palm empty fruit bunches have been done by using batch method. The optimum lignin isolation method was achieved through this study. The study was conducted on the optimization of reaction temperature, mass ratio of $\mathrm{NaOH}$ to the solvent, the ratio of fibers to solvents, and reaction time. Of all the treatments, it was found that the reaction optimum temperature, system pressure, concentration of $\mathrm{NaOH}$, the ratio of fibers to solvents and reaction time respectively, $170{ }^{\circ} \mathrm{C}, 15 \mathrm{~atm}, 1 \%(\mathrm{w} / \mathrm{v}), 9 \%(\mathrm{w} / \mathrm{v})$, and the reaction was carried out for 5 hours.
\end{abstract}

Keyword: lignin, isolation, oil palm empty fruit bunches

\section{Pendahuluan}

Menurut Cakrabawa dan Nuryati

pada tahun 2014, rata-rata pertumbuhan

produktivitas kelapa sawit Indonesia

mengalami peningkatan dimana

produktivitas tertinggi dicapai pada tahun

2013 sebesar 3,85 ton/ha. Industri ini

merupakan sektor ekspor pertanian yang

paling tinggi nilainya (World Growth,

2011).

Ekspor-impor kelapa sawit

Indonesia dilakukan dalam wujud minyak

sawit dan perkembangan volume ekspornya cenderung terus meningkat. Hal tersebut berpengaruh secara langsung pada limbah padat yang dihasilkan industri minyak kelapa sawit yaitu tandan kosong kelapa sawit (TKKS) (Dirjen Perkebunan, 2005).

Tandan kosong kelapa sawit (TKKS) merupakan limbah industri Crude Palm Oil (CPO) yang sangat melimpah. Ketersediaan TKKS sangat menjanjikan bila ditinjau dari jumlah rata-rata nisbah produksi TKKS terhadap tandan buah segar dimana rerata produksi tandan 
kosong kelapa sawit adalah berkisar 22\% hingga 24\% dari total berat tandan buah segar (Arif, 2012).

Sampai saat ini, TKKS secara umum baru dimanfaatkan sebagai bahan baku pupuk kompos dan mulsa di kebun (Simatupang et al., 2012). Pemanfaatan TKKS terkesan minimal bila melihat potensi dari kandungan lignoselulosa TKKS yang cukup tinggi. Kandungan TKKS meliputi selulosa (41-46,5\%), hemiselulosa $(25,3-33,8 \%)$, dan lignin (27,6-32,5\%) (Suriyani, 2009).

Kandungan TKKS yang dapat dimaksimalkan pemanfaatannya adalah lignin. Lignin dapat dimanfaatkan sebagai bahan perekat, pengikat, dispersan, surfaktan, produk polimer, dan sumber bahan kimia lainnya (Fenger dan Wegener, 1995).

Lignin dapat dimanfaatkan sebagai sumber bahan kimia karena lignin mempunyai gugus aktif yang dapat direaksikan dengan gugus lain sehingga menghasilkan senyawa baru. Secara umum lignin tersusun atas unit guaiasil, siringil, parahidroksil propana, $-\mathrm{OH}$, dan beberapa gugus aldehida ujung dalam rantai samping (Sarkanen et al., 1980).

Melihat dari banyaknya manfaat lignin, maka beberapa peneliti mulai melakukan penelitian dalam bidang isolasi lignin dari bahan baku kayu dan lain-lain.

$$
\text { Simatupang et al. }
$$

mengisolasi lignin dari TKKS dengan menggunakan digester pada suhu $170{ }^{\circ} \mathrm{C}$. Rendemen lignin yang diperoleh yaitu $16,42 \%$ dengan perlakuan pemasakan 2 jam dengan penambahan $\mathrm{NaOH} 20 \%$ dan proses pengenceran lindi hitam 1:2. Dalam penelitian ini pula, sebelum pemasakan dilakukan ekstraksi menggunakan benzena : etanol 96\% dengan perbandingan 2:1 untuk menghilangkan zat ekstraktif.

Rambe et al. (2013) juga mencoba untuk melakukan studi isolasi lignin dengan melakukan variasi konsentrasi $\mathrm{NaOH}$. Rendemen terbesar (16,42\%) didapatkan pada penggunaan $\mathrm{NaOH}$ dengan konsentrasi 20\%. Hal ini tidak jauh berbeda dengan apa yang sudah dikemukakan oleh Simatupang et al. (2012).

Proses isolasi yang dilakukan oleh Simatupang et al. (2012) dan Rambe et al. (2013) ini sangatlah panjang dan cukup berbahaya karena harus didahului ekstraksi menggunakan benzena yang merupakan senyawa beracun. Selain itu, pada penelitian tersebut terlalu banyak menggunakan $\mathrm{NaOH}$ yaitu dengan konsentrasi sebesar $20 \%$ pada proses 
delignifikasi sehingga dalam proses netralisasi akan membutuhkan asam yang cukup banyak.

Oleh karena itu, dalam penelitian ini akan dilakukan proses isolasi lignin atau dikenal dengan proses delignifikasi dengan menggunakan sistem autoklaf dimana $\mathrm{NaOH}$ yang digunakan seminimal mungkin dan tanpa didahului proses ekstraksi menggunakan kombinasi antara benzena dan etanol. Penelitian dilakukan untuk mengetahui kondisi optimum reaksi untuk menghasilkan rendemen terbaik.

\section{Tujuan Penelitian}

Tujuan yang akan dicapai dalam penelitian ini yaitu menentukan kondisi optimum pada proses isolasi lignin yang meliputi suhu, tekanan, konsentrasi $\mathrm{NaOH}$, rasio TKKS dengan pelarut dan waktu reaksi.

\section{Metode Penelitian}

Alat

Peralatan yang digunakan pada penelitian ini yaitu seperangkat alas gelas, seperangkat autoklaf kapasistas $2 \mathrm{~L}, \mathrm{pH}$ meter, shredder, penyaring Buchner, kertas saring Whatman-42, oven, spektrometer infra merah (IR, Shimadzu Prestige-21) dan magnetic stirrer.

\section{Bahan}

Bahan-bahan yang digunakan pada penelitian ini adalah serabut TKKS, $\mathrm{NaOH}$ (pa), etanol teknis 96\%, akuades, dan $\mathrm{H}_{2} \mathrm{SO}_{4} 10 \%$.

\section{Cara Kerja}

\section{Preparasi Sampel}

Sebanyak 100 gram serabut TKKS dikeringkan menggunakan oven pada suhu $100 \quad{ }^{\circ} \mathrm{C}$ kemudian dihancurkan menggunakan shredder menjadi ukuran 10 mesh. Sampel kemudian ditambahkan akuades 1 L dan dipanaskan pada suhu $100{ }^{\circ} \mathrm{C}$ selama 2 jam. Kemudian sampel difiltrasi dan dikeringkan sehingga siap digunakan.

\section{Penentuan suhu dan tekanan optimum}

Sebanyak 100 gram serbuk TKKS 10 mesh dimasukkan ke dalam autoklaf dan ditambahkan $1 \mathrm{~L}$ larutan $2 \% \mathrm{NaOH}$ dalam akuadest : etanol 96\% 1:1. Sistem dipanaskan selama 5 jam dengan variasi suhu 160,170 dan $180^{\circ} \mathrm{C}$ dimana masingmasing memiliki tekanan terukur secara berturut-turut 13, 15 dan 16 atmosfer. Sampel disaring dan diambil larutan lindi hitam yang terbentuk. Pada larutan lindi hitam dilakukan pengasaman menggunakan $\mathrm{H}_{2} \mathrm{SO}_{4} \quad 10 \%$ sampai $\mathrm{pH} 2$. Campuran kemudian didiamkan selama 8 jam sampai terbentuk padatan. Padatan 
(lignin) yang terbentuk kemudian disaring menggunakan whatman 42 dan dipanaskan menggunakan oven pada suhu $60{ }^{\circ} \mathrm{C}$. Padatan lignin dari setiap variasi suhu dianalisis menggunakan spektrometer infra merah, ditimbang dan dihitung rendemennya untuk menentukan suhu dan tekanan optimum.

\section{Penentuan konsentrasi $\mathrm{NaOH}$ optimum} dalam 1L pelarut etanol/akuades 1:1

Sebanyak 100 gram serbuk TKKS 10 mesh dimasukkan ke dalam autoklaf dan ditambahkan 1 L larutan $\mathrm{NaOH}$ dalam akuadest : etanol 96\% 1:1 dengan variasi konsentrasi masing-masing $1 \%, 2 \%, 3 \%$ dan 4\% (b/v). Sistem dipanaskan selama 5 jam pada suhu dan tekanan optimum. Larutan lindi hitam yang terbentuk kemudian disaring dan diasamkan seperti perlakuan sebelumnya sampai didapatkan lignin. Padatan lignin dari setiap variasi konsentrasi dianalisis menggunakan spektrometer infra merah, ditimbang dan dihitung rendemennya untuk menentukan konsentrasi $\mathrm{NaOH}$ optimum.

\section{Penentuan rasio serbuk TKKS dengan} pelarut

Sebanyak 70, 80, 90 dan 100 gram serbuk TKKS 10 mesh dimasukkan ke dalam autoklaf dan ditambahkan 1 L larutan $\mathrm{NaOH}$ dalam akuadest : etanol 96\%
1:1 sesuai dengan konsentrasi optimum. Sistem dipanaskan selama 5 jam dengan suhu dan tekanan optimum. Larutan lindi hitam yang terbentuk disaring dan diasamkan seperti perlakuan sebelumnyasampai didapatkan lignin. Padatan lignin dari setiap variasi rasio TKKS/pelarut dianalisis menggunakan spektrometer infra merah, ditimbang dan dihitung rendemennya untuk menentukan rasio $\mathrm{TKKS} /$ pelarut (b/v) yang optimum.

\section{Penentuan waktu reaksi optimum}

Sebanyak 90 gram serbuk TKKS 10 mesh dimasukkan ke dalam autoklaf dan ditambahkan $1 \mathrm{~L}$ larutan $\mathrm{NaOH}$ dalam akuadest : etanol 96\% 1:1 sesuai dengan konsentrasi optimum. Sistem dipanaskan pada variasi waktu reaksi 1, 2, 3, 4 dan 5 jam dengan suhu dan tekanan optimum. Larutan lindi hitam yang terbentuk kemudian disaring dan diasamkan seperti dengan perlakuan sebelumnya. Padatan lignin dari setiap variasi waktu reaksi dianalisis menggunakan spektrometer infra merah, ditimbang dan dihitung rendemennya untuk menentukan waktu reaksi yang optimum.

\section{Pembahasan}

Penelitian ini bersifat eksploratif dimana nantinya akan didapatkan hasil akhir berupa kondisi optimum reaksi 
isolasi lignin atau delignifikasi. Reaksi delignifikasi merupakan reaksi yang sudah umum dilakukan terutama di industri pembuatan kertas.

Dari sekian banyak variasi kondisi yang dilakukan, rendemen tertinggi dari proses isolasi lignin adalah 14,1\%. Angka ini merupakan nilai perbandingan antara berat kering lignin dengan berat serbuk TKKS. Sementara itu, rendemen lignin terendah adalah $7,31 \%$ pada isolat lignin dengan perlakuan delignifikasi selama 5 jam dengan penambahan $\mathrm{NaOH} 2 \%$ dan pada suhu reaksi $180{ }^{\circ} \mathrm{C}$ dimana rasio antara TKKS dengan pelarut sebesar $10 \%$. Sedangkan nilai rendemen lignin tertinggi adalah $14,1 \%$ pada isolat lignin dengan perlakuan delignifikasi selama 5 jam dengan penambahan $\mathrm{NaOH} 1 \%$ dan pada suhu reaksi $170{ }^{\circ} \mathrm{C}$ dimana rasio antara TKKS dengan pelarut sebesar $9 \%$.

Tabel 1. Hasil isolasi lignin dengan variasi suhu reaksi delignifikasi

\begin{tabular}{|c|c|c|c|c|c|}
\hline $\begin{array}{c}\text { Serbuk TKKS } \\
(\mathrm{g})\end{array}$ & $\begin{array}{c}\text { NaOH dalam } \\
\text { pelarut }(\% \mathrm{~b} / \mathrm{v})\end{array}$ & Waktu (jam) & Suhu $\left({ }^{\circ} \mathrm{C}\right)$ & $\begin{array}{c}\text { Tekanan } \\
(\mathrm{atm})\end{array}$ & $\begin{array}{c}\text { Lignin } \\
(\%)\end{array}$ \\
\hline 100 & 2 & 5 & 160 & 13 & 10 \\
\hline $\mathbf{1 0 0}$ & $\mathbf{2}$ & $\mathbf{5}$ & $\mathbf{1 7 0}$ & $\mathbf{1 5}$ & $\mathbf{1 3}$ \\
\hline 100 & 2 & 5 & 180 & 16 & 7,31 \\
\hline
\end{tabular}

Dari Tabel 1 dapat dilihat bahwa rendemen lignin tertinggi didapatkan pada suhu reaksi $170{ }^{\circ} \mathrm{C}$ dengan tekanan sistem yang terbaca sebesar $15 \mathrm{~atm}$. Pada tahapan ini, massa serbuk TKKS, konsentrasi $\mathrm{NaOH}$ dan waktu reaksi dibuat konstan sehingga dapat terlihat jelas efek yang ditimbulkan dari perbedaan suhu dan tekanan reaksi. Selain itu, didapatkan informasi bahwa rendemen lignin menurun drastis pada suhu reaksi $180{ }^{\circ} \mathrm{C}$. Hal ini dimungkinkan karena terjadinya degradasi senyawa lignin pada suhu dan tekanan tinggi.
Setelah didapatkan suhu dan tekanan optimum, dilakukan variasi konsentrasi $\mathrm{NaOH}(\mathrm{b} / \mathrm{v})$ dalam sistem reaksi. Dalam hal ini beberapa parameter reaksi seperti massa serbuk TKKS, waktu reaksi, suhu dan tekanan reaksi dibuat konstan yaitu masing-masing $100 \mathrm{~g}, 5$ jam $170{ }^{\circ} \mathrm{C}$ dan 15 atm. Massa $\mathrm{NaOH}$ yang dilarutkan dalam 1 L pelarut etanol : akuades (1:1) berturut-turut adalah $10 \mathrm{~g}$ $(1 \% \mathrm{~b} / \mathrm{v}), 20 \mathrm{~g}(2 \% \mathrm{~b} / \mathrm{v}), 30 \mathrm{~g}(3 \% \mathrm{~b} / \mathrm{v})$ dan $40 \mathrm{~g}(4 \% \mathrm{~b} / \mathrm{v})$. Data dari proses ini disajikan pada Tabel 2. 
Tabel 2. Hasil isolasi lignin dengan variasi konsentrasi $\mathrm{NaOH}$

\begin{tabular}{|c|c|c|c|c|c|}
\hline $\begin{array}{c}\text { Serbuk TKKS } \\
(\mathrm{g})\end{array}$ & $\begin{array}{c}\text { NaOH dalam } \\
\text { pelarut } \\
(\% \mathrm{~b} / \mathrm{v})\end{array}$ & Waktu (jam) & Suhu $\left({ }^{\circ} \mathrm{C}\right)$ & $\begin{array}{c}\text { Tekanan } \\
(\text { atm })\end{array}$ & $\begin{array}{c}\text { Lignin } \\
(\%)\end{array}$ \\
\hline $\mathbf{1 0 0}$ & $\mathbf{1}$ & $\mathbf{5}$ & $\mathbf{1 7 0}$ & $\mathbf{1 5}$ & $\mathbf{1 3 , 6}$ \\
\hline 100 & 2 & 5 & 170 & 15 & 13 \\
\hline 100 & 3 & 5 & 170 & 15 & 9,24 \\
\hline
\end{tabular}

Dari Tabel 2 diperoleh informasi bahwa pada variasi konsentrasi $\mathrm{NaOH} 1 \%$ didapatkan rendemen lignin tertinggi yaitu sebesar 13,6\%. Semakin rendahnya konsentrasi $\mathrm{NaOH}$ yang digunakan ternyata membuat reaksi lebih efektif sehingga rendemen yang didapatkanpun meningkat.

Fenomena ini erat kaitannya dengan faktor pengenceran dari $\mathrm{NaOH}$.
Simatupang et al. (2012) dalam penelitiannya menjelaskan bahwa semakin besar nilai pengenceran yang dilakukan maka rendemen lignin yang didapatkan semakin meningkat walaupun tetap terdapat batas nilai pengenceran optimum. Peningkatan konsentrasi $\mathrm{NaOH}$ berbanding lurus dengan semakin kecilnya angka pengenceran. Hal ini yang membuat rendemen lignin menurun.

Tabel 3. Hasil isolasi lignin dengan variasi rasio serabut TKKS dengan pelarut

\begin{tabular}{|c|c|c|c|c|c|}
\hline $\begin{array}{c}\text { Serbuk TKKS } \\
(\mathrm{g})\end{array}$ & $\begin{array}{c}\mathrm{NaOH} \text { dalam pelarut } \\
(\% \mathrm{~b} / \mathrm{v})\end{array}$ & $\begin{array}{c}\text { Waktu } \\
(\mathrm{jam})\end{array}$ & $\begin{array}{c}\text { Suhu } \\
\left({ }^{\circ} \mathrm{C}\right)\end{array}$ & $\begin{array}{c}\text { Tekanan } \\
(\mathrm{atm})\end{array}$ & $\begin{array}{c}\text { Lignin } \\
(\%)\end{array}$ \\
\hline 100 & 1 & 5 & 170 & 15 & 13,6 \\
$\mathbf{9 0}$ & $\mathbf{1}$ & $\mathbf{5}$ & $\mathbf{1 7 0}$ & $\mathbf{1 5}$ & $\mathbf{1 4 , 1}$ \\
80 & 1 & 5 & 170 & 15 & 11 \\
70 & 1 & 5 & 170 & 15 & 7,8 \\
\hline
\end{tabular}

Pada Tabel 3 disajikan data variasi rasio serabut TKKS dengan pelarut etanol:akuades (1:1). Rendemen lignin tertinggi didapatkan pada perbandingan serabut TKKS dengan pelarut $9: 100(\mathrm{~b} / \mathrm{v})$ atau dengan kata lain $9 \%(\mathrm{~b} / \mathrm{v})$.

Secara umum semakin tinggi rasio antara serbuk TKKS dengan pelarut akan meningkatkan rendemen lignin. Akan tetapi setelah mencapai rasio tertentu terjadi penurunan rendemen lignin. Hal ini terjadi pada rasio TKKS/pelarut sebesar $10 \%(\mathrm{~b} / \mathrm{v})$. Ini menandakan bahwa terdapat rasio optimum antara TKKS dengan pelarut yang dapat menghasilkan rendemen lignin yang optimal pula. 
Tabel 4. Hasil isolasi lignin dengan variasi waktu reaksi

\begin{tabular}{|c|c|c|c|c|c|}
\hline $\begin{array}{c}\text { Serbuk TKKS } \\
(\mathrm{g})\end{array}$ & $\begin{array}{c}\text { NaOH dalam pelarut } \\
(\% \mathrm{~b} / \mathrm{v})\end{array}$ & $\begin{array}{c}\text { Waktu } \\
(\mathrm{jam})\end{array}$ & $\begin{array}{c}\text { Suhu } \\
\left({ }^{\circ} \mathrm{C}\right)\end{array}$ & $\begin{array}{c}\text { Tekanan } \\
(\mathrm{atm})\end{array}$ & $\begin{array}{c}\text { Lignin } \\
(\%)\end{array}$ \\
\hline 90 & 1 & 2 & 170 & 15 & 8,8 \\
90 & 1 & 3 & 170 & 15 & 11,7 \\
90 & 1 & 4 & 170 & 15 & 13,5 \\
$\mathbf{9 0}$ & $\mathbf{1}$ & $\mathbf{5}$ & $\mathbf{1 7 0}$ & $\mathbf{1 5}$ & $\mathbf{1 4 , 1}$ \\
90 & 1 & 6 & 170 & 15 & 13,3 \\
\hline
\end{tabular}

Dari Tabel 4, diperoleh informasi waktu reaksi isolasi lignin yang optimum dimana dihasilkan rendemen lignin terbesar yaitu pada waktu reaksi 5 jam. Ini dikarenakan pada waktu reaksi 5 jam diperoleh rendemen lignin tertinggi yaitu sebesar $14,1 \%$. Semakin lama waktu reaksi, semakin tinggi rendemen yang didapatkan walaupun terjadi penurunan setelah melewati waktu reaksi optimum.

Hal ini dapat terjadi dikarenakan kontak atau singgungan antara pelarut, $\mathrm{NaOH}$ dan serabut membutuhkan waktu yang cukup lama walaupun di dalam sistem telah diberikan sarana pemercepat seperti suhu yang tinggi dan pengaduk yang berputar konstan. Fenomena ini sungguh berbeda dengan hasil penelitian yang dikemukakan oleh Simatupang et al. (2012) dan Rambe et al. (2013) dimana hanya dibutuhkan waktu reaksi 2 jam.

Walaupun membutuhkan waktu reaksi yang lebih lama, namun dalam penelitian ini didapatkan fakta bahwa $\mathrm{NaOH}$ yang digunakan cukup sedikit atau tidak mencapai $20 \%$. Selain itu, dengan tidak melakukan proses ekstraksi di awal menggunakan benzena : etanol tidak terlalu mempengaruhi hasil rendemen yang didapatkan. Rendemen yang didapatkan tidak terlalu berbeda signifikan dengan metode yang dikembangkan oleh Simatupang et al. (2012) dan Rambe et al. (2013) karena hanya berselisih 2\%.

\section{Uji FT-IR Senyawa Lignin}

Untuk mengetahui keberhasilan proses isolasi lignin maka harus dilakukan identifikasi gugus fungsi yang ada. Analisis ini dilakukan menggunakan spektrometer FT-IR yang mampu mengidentifikasi serapan-serapan khas untuk masing-masing gugus fungsi.

Menurut Hergert (1971), senyawa lignin secara umum diidentifikasi dengan munculnya beberapa gugus penyusun seperti serapan pada bilangan gelombang 3400-3450 $\mathrm{cm}^{-1}$ untuk regang $\mathrm{OH}, 2820$ $2940 \mathrm{~cm}^{-1}$ untuk regang C-H metil, 1600 $1515 \mathrm{~cm}^{-1}$ untuk cincin aromatik, 1460 $1470 \mathrm{~cm}^{-1}$ untuk regang $\mathrm{C}-\mathrm{H}$ asimetri, 
1330-1315 $\mathrm{cm}^{-1}$ untuk regang cincin stringil, $1270-1280 \mathrm{~cm}^{-1}$ untuk cincin guasil, 1030-1085 $\mathrm{cm}^{-1}$ untuk regang eter dan $850-875 \mathrm{~cm}^{-1}$ untuk C-H aromatik.

Berdasarkan spektra IR dan dengan membandingkan gugus senyawa lignin standar dengan lignin yang dihasilkan dari penelitian ini maka dapat dilihat bahwa terdapat kemiripan dan sangat relevan dengan gugus umum yang terdapat dalam lignin. Oleh karena itu dapat disimpulkan bahwa senyawa yang berhasil diisolasi merupakan lignin.

Tabel 5. Hasil analisis spektra IR lignin

\begin{tabular}{|l|c|c|}
\hline \multicolumn{1}{|c|}{$\begin{array}{c}\text { Fugus } \\
\text { Fungsi }\end{array}$} & $\begin{array}{c}\text { Bilangan } \\
\text { Gelombang } \\
\left(\mathrm{cm}^{-1}\right)\end{array}$ & $\begin{array}{c}\text { Standar Kisaran } \\
\text { Pita Serapan } \\
\left(\mathrm{cm}^{-1}\right)\end{array}$ \\
\hline Uluran O-H & 3425 & $3400-3450$ \\
\hline $\begin{array}{l}\text { Uluran } \\
\text { C-H metil }\end{array}$ & $\begin{array}{c}2924 \text { dan } \\
2854\end{array}$ & $2820-2940$ \\
\hline $\begin{array}{l}\text { Cincin } \\
\text { aromatis }\end{array}$ & $\begin{array}{c}1512 \text { dan } \\
1604\end{array}$ & $\begin{array}{c}1505-1515 \text { dan } \\
1600-1610\end{array}$ \\
\hline $\begin{array}{l}\text { C-H } \\
\text { asimetri }\end{array}$ & 1458 & $1450-1470$ \\
\hline $\begin{array}{l}\text { Cincin } \\
\text { Siringil }\end{array}$ & 1327 & $1315-1330$ \\
\hline $\begin{array}{l}\text { Cincin } \\
\text { Guaiasil }\end{array}$ & 1219 & $1270-1280$ \\
\hline Uluran Eter & 1033 & $1030-1085$ \\
\hline $\begin{array}{l}\text { C-H } \\
\text { aromatis }\end{array}$ & 840 & $850-875$ \\
\hline
\end{tabular}

\section{Kesimpulan}

Telah didapatkan kondisi optimum untuk proses isolasi lignin dari serbuk tandan kosong kelapa sawit. Reaksi dilakukan pada suhu reaksi $170{ }^{\circ} \mathrm{C}$, pada tekanan 15 atmosfir dengan konsentrasi $\mathrm{NaOH}$ terhadap pelarut $1 \%(\mathrm{~b} / \mathrm{v})$, rasio serabut TKKS terhadap pelarut $9 \%(\mathrm{~b} / \mathrm{v})$, dan reaksi dilakukan selama 5 jam.

\section{Pustaka}

Arif, Z., 2012, Respon Parking Bumper Bahan Komposit Polymeric Foam Diperkuat Serat Tandan Kosong Kelapa Sawit (Tkks) Akibat Beban Tekan Statik Dan Dinamik (Simulasi Numerik), Tesis Master, Universitas Sumatera Utara.

Cakrabawa, D.N., dan Nuryati, L., 2014, Outlook Komoditi Kelapa Sawit, Pusat Data dan Sistem Informasi Pertanian Sekretariat Jenderal Kementerian Pertanian, ISSN 1907-1507

DirJen Perkebunan, 2005, Statistika Perkelapa Sawitan Indonesia, Departemen Pertanian, DirJen Perkebunan Indonesia, Jakarta.

Fenger, D. dan Wegener, G., 1995, Kayu : Kimia, Ultrastruktur, ReaksiReaksi, Diterjemaahkan oleh Sastrohamidjojo, H. Terjemahan dari : Wood : Chemical, Ultrastructure, Reactions. Gadjah Mada University Press, Yogyakarta.

Hergert, H. L. 1971. Infrared Spectra. Willey Interscience, New York. 267-297. 
Rambe, M., Nata, A., dan Herlina, N., 2013, Pengaruh Katalis $\mathrm{NaOH}$ pada Proses Isolasi Lignin dari Tandan Kosong Kelapa Sawit, Jurnal Teknik Kimia USU, 2, 25-27.

Sarkanen, K., V. S. Assiz and V. Chiang. 1980. Organosolv Pulping. Semi annual Report I and II. College of Forest Resources, Univ. of Washington, New York.

Simatupang, H., Nata, A., dan Herlina, N., 2012, Studi Isolasi dan Rendemen Lignin Dari Tandan Kosong Kelapa
Sawit (TKKS), Jurnal Teknik Kimia USU, 1, 20-24.

Suriyani, Y., 2009, Utilization of Biomass Waste Empty Fruit Bunch Fiber of Palm Oil for Bioethanol Production, Jakarta 4-5 Februari 2009 : Research Workshop on Sustainable Biofuel : 115.

World Growth, 2011, Manfaat Minyak Sawit Bagi Perekonomian Indonesia, World Growth Arlington, VA 22203-3693 